\title{
Fertility of cryopreserved ovine semen is determined by sperm velocity
}

\author{
Q1 E. Del Olmo ${ }^{\text {a }}$ A. Bisbal a ${ }^{\text {a }}$ A. Maroto-Morales ${ }^{\mathrm{a}}$, O. García-Alvarez ${ }^{\mathrm{a}}$, M. Ramon ${ }^{\mathrm{b}}$, \\ P. Jimenez-Rabadan ${ }^{\text {b }}$, F. Martínez-Pastor ${ }^{\text {c }}$, A.J. Soler ${ }^{\mathrm{a}}$, J.J. Garde ${ }^{\mathrm{a}}$, \\ M.R. Fernandez-Santos ${ }^{\mathrm{a}, *}$ \\ a Biology of Reproduction Group, National Wildlife Research Institute (IREC) UCLM-CSIC-JCCM, 02071 Albacete, Spain \\ b Regional Center of Animal Selection and Reproduction (CERSYRA) JCCM, 13300 Valdepeñas, Spain \\ c ITRA-ULE, INDEGSAL, University of León, León, Spain
}

\section{A R T I C L E I N F O}

\section{Article history:}

Received 12 July 2012

Received in revised form 6 February 2013

Accepted 8 February 2013

Available online $\mathrm{xxx}$

\section{Keywords:}

Fertility

Cryopreserved semen

Ram

Flow cytometry

CASA

\begin{abstract}
A B S T R A C T
The present study aims to examine the predictive value of some sperm parameters on male fertility. Semen samples from six Manchega rams were collected and cryopreserved. Sperm quality was assessed after thawing and after $2 \mathrm{~h}$ of incubation, either in the freezing exten$\operatorname{der}\left(37^{\circ} \mathrm{C}\right)$ or after dilution in Synthetic Oviductal Fluid (SOF) $\left(38^{\circ} \mathrm{C}, 5 \% \mathrm{CO}_{2}\right)$, attempting to mimic the physiological conditions of the female reproductive tract. The following sperm parameters were evaluated: motility and kinetic parameters by computer-assisted semen analyzer (CASA), and sperm viability (propidium iodide), mitochondrial membrane potential (JC-1), apoptotic-like membrane changes (YO-PRO-1), acrosomal status (PNA-FITC), and intracellular calcium (fluo-3) by flow cytometry. Results showed no significant differences between incubation media neither after thawing nor after incubation. There were no significant correlations between fertility and sperm parameters assessed by flow cytometry. However, after incubation in the freezing extender, sperm samples from males with poor fertility yielded less linearity and velocity $(P<0.05)$ as indicated by motility parameters analyzed by CASA. These results indicate that kinematic sperm motility parameters evaluation by CASA might be useful to identify samples with poor fertility.
\end{abstract}

(C) 2013 Published by Elsevier B.V.

\section{Introduction}

The assessment of the fertility potential of a semen sample has been the paramount objective of semen analysis, to predict the outcome of a future artificial insemination. Many studies have aimed at uncovering this relationship between sperm quality parameters and in vivo fertility, with different outcomes (Papadopoulos et al., 2005; Rodríguez-Martínez, 2003; Schneider et al., 1999; Zhang et al., 1998). Conventional semen assessment using light microscopy has been increasingly replaced

\footnotetext{
* Corresponding author at: ETSIA, Campus Universitario s/n, 02071Albacete, España. Tel.: +34 967599 200/2581; fax: +34 967599238.

E-mail address: MRocio.Fernandez@uclm.es (M.R. Fernandez-Santos).
}

by fluorescent staining techniques, flow cytometry and computer-assisted sperm analysis (CASA) (Hallap et al., 2006). Moreover, an increasing number of techniques for in vitro semen evaluation have aimed at evaluating more precisely characteristics of the sperm that are essential for fertility. However, any study has yielded a conclusive link among sperm quality and fertility.

Thus, the objective in the present study was to explore laboratory techniques that would allow to quickly and effectively evaluate the potential fertility of a sperm sample. The present study follows the previous study by García-Alvarez et al. (2009a), which showed that heterologous in vitro fertilization assays were related to ram sperm fertility. In the present study, it was decided to study the behavior of sperm samples after incubation in the same medium used for in vitro fertilization, to determine if after 
"physiological-like" incubation the relation of sperm quality tests with fertility results would be improved.

To perform the present study, we have focused in flow cytometry as a tool with great statistical power because of its ability to analyze thousands of cells in a few seconds, improving existing analyses of fluorescence microscopy and allowing for new multi-parametric analyses (Martínez-Pastor et al., 2010). There have been many attempts to correlate flow cytometry results and fertility (Gillan et al., 2003). For instance, mitochondrial function and membrane integrity with fertility after artificial insemination with ram (Soler et al., 2008) or bull (Gualtieri et al., 2005) semen. However, García-Alvarez et al. (2009a) did not find any relation to fertility with the following sperm parameters: viability (PI membrane exclusion), membrane stability (YOPRO1), membrane phospholipid disorder (M540), and mitochondrial membrane potential (Mitotracker Deep Red), all assessed by flow cytometry. This study is a further step, testing additional sperm parameters in a modified experimental setting, to clarify the relation of several sperm variables to fertility.

Thus, with the present study it was decided to evaluate different sperm parameters and their relation to in vivo fertility, to study whether these assays have the attributes to determine the potential fertility of a sperm sample. Acrosomal status (peanut agglutinin - PNA - conjugated with fluorescein), viability and apoptosis (using the fluorochromes propidium iodide (PI) and YOPRO1, respectively) were evaluated because the activation of apoptotic pathways could be responsible for poor fertility resulting from use of a sperm sample for artificial insemination. Moreover, the presence of active mitochondria is important because they participate in many regulatory and maintenance processes, and could also be linked to sperm death (Aitken et al., 2007), so mitochondrial activity (JC-1) was evaluated.

Calcium is an intracellular messenger that has a key role in sperm capacitation. Recently, Marquez and Suarez (2007) established the relationship among capacitation status and intracellular calcium concentration in frozen-thawed sperm. In this regard, intracellular calcium concentrations were analyzed as a factor related to sperm capacitation (fluo-3) (Maxwell and Watson, 1996).

To fully address this topic, sperm motility was evaluated using a computer-assisted semen analyzer (CASA) which provides precise and accurate information on sperm kinematic parameters (Gravance and Davis, 1995), allowing a more accurate prediction of fertility than the parameters assessed by the routine microscopic semen evaluation (Farrell et al., 1998; Malo et al., 2005). The objective assessment of sperm function could increase the chances of predicting the fertilizing capacity of a frozen-thawed semen sample or diagnosing infertility problems.

\section{Materials and methods}

\subsection{Reagents and media}

Flow cytometry equipment, software and consumables were purchased from Beckman Coulter (Fullerton, CA, USA). The remaining of the chemicals (Reagent grade or higher) and propidium iodide (PI) were acquired from Sigma (Madrid, Spain). Other fluorescent probes were purchased from Invitrogen (Barcelona, Spain). Stock solutions of the fluorescence probes were: $7.5 \mathrm{mM} \mathrm{PI}$ in water; $50 \mu \mathrm{m}$ YOPRO1 in DMSO; $100 \mu \mathrm{g} / \mathrm{mL}$ FITC-

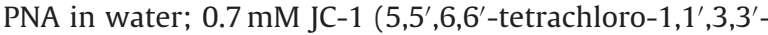
tetraethylbenzimidazolylcarbocyanine iodide) in DMSO; $5 \mu \mathrm{M}$ fluo-3 in DMSO.

All fluorescent stocks were kept at $-20^{\circ} \mathrm{C}$, in the dark until needed. The freezing extender was prepared using reagent-grade chemicals purchased from Panreac Química S.A. (Barcelona, Spain) and Sigma Chemical Co. (St. Louis, Missouri, USA). The fluorochrome acridine orange was of electrophoretic grade and purchased from Polysciences Inc. (Warrington, PA, USA).

Syntetic Oviductal Fluid (SOF) was composed of: $\mathrm{NaCl}$ $107 \mathrm{mM}, \quad \mathrm{KCl} 7.17 \mathrm{mM}, \mathrm{KH}_{2} \mathrm{PO}_{4} 1.19 \mathrm{mM}, \mathrm{Ca}_{2} \mathrm{Cl} \cdot 2 \mathrm{H}_{2} \mathrm{O}$ $1.71 \mathrm{mM}, \mathrm{MgCl}_{2} \cdot 6 \mathrm{H}_{2} \mathrm{O} 0.49 \mathrm{mM}, \mathrm{NaHCO}_{3} 25.07 \mathrm{mM}$, Na lactate $3.3 \mathrm{mM}$, Na pyruvate $0.3 \mathrm{mM}$ and glutamine $200 \mathrm{mM}$.

\subsection{Animals and semen collection}

All animal procedures were performed in accordance with Spanish Animal Protection Regulation RD1201/2005, which conforms to European Union Regulation 2003/65. Adult males belong to the Regional Center for Animal Selection and Reproduction in Valdepeñas (CERSYRA). Six males of white Manchega sheep breed (age $>3$ years) were used. Males were selected based on average fertility by artificial insemination. Thus, three males were selected with an average fertility over $50 \%$ and three males with an average fertility under $50 \%$. After males were chosen, semen collection, and the intrauterine insemination and the assessment of sperm quality was performed. Semen collection was performed with an artificial vagina. The volume, concentration, mass motility ( 0 : no movement to 5: strong movement) and motility (\%) immediately after collection were evaluated. Only the ejaculates with mass movement greater than 4 and individual motility greater than $80 \%$ after $10 \mathrm{~min}$ in a warm bath at $37^{\circ} \mathrm{C}$ were used in the present study.

\subsection{Cryopreservation of semen}

After initial semen evaluation, each ejaculate was diluted with the freezing extender. The extender used was prepared as described by Fiser et al. (1987). Fraction 1 was added 3:2 to semen and the sample was slowly cooled from $30^{\circ} \mathrm{C}$ to $5^{\circ} \mathrm{C}$ for $2 \mathrm{~h}$. Then, the samples were further diluted (3:1) with Fraction 2 at $5^{\circ} \mathrm{C}$, reaching a final concentration of $200 \times 10^{6} \mathrm{sperm} / \mathrm{mL}$, and held at this temperature for equilibration for $2 \mathrm{~h}$ (total refrigeration time at $5^{\circ} \mathrm{C}$ was $4 \mathrm{~h}$ ). At the end of the cooling and equilibration period, the extended semen was loaded into $0.25-\mathrm{ml}$ plastic straws and frozen. The straws were frozen in a programmable biofreezer (Planner) at $-20^{\circ} \mathrm{C} / \mathrm{min}$ to $-100^{\circ} \mathrm{C}$, and at $-10^{\circ} \mathrm{C} / \mathrm{min}$ from $-100^{\circ} \mathrm{C}$ to $-140^{\circ} \mathrm{C}$ and then plunged into liquid nitrogen. Thawing was performed by putting the straws in a water bath with saline at $37^{\circ} \mathrm{C}$ for $30 \mathrm{~s}$, and the contents were transferred into a glass tube. 


\subsection{Artificial insemination trials}

Thawed sperm samples from the six males were used to inseminate 551 ewes in eight farms. Sperm samples from each male were used to inseminate between 11 and 262 females. The ewes were synchronized using progestagen pessaries (30 mg fluorogestone acetate, FGA; Chronogest, Intervet, The Netherlands) for $13 \mathrm{~d}$ followed by $500 \mathrm{IU}$ equine chorionic gonadotrophin (eCG) at pessary removal. Ewes were inseminated intrauterine by laparoscopy at 55-58 $\mathrm{h}$ after pessary removal. Two technicians performed all intrauterine inseminations in different dates.

A male was considered to have contributed to a successful fertilization when the female lambed. Fertility rate for each male was calculated as follows: number of lambed ewes/number of ewes inseminated $\times 100$. This rate was called male fertility.

\subsection{Assessment of frozen-thawed sperm}

Thawed samples were incubated for $2 \mathrm{~h}\left(37^{\circ} \mathrm{C}\right)$ without dilution (i.e., in the freezing extender) or after dilution 1:25 in SOF medium, at $5 \% \mathrm{CO}_{2}\left(38^{\circ} \mathrm{C}\right)$. Samples were analyzed after this incubation time by CASA and flow cytometry. Sperm motility (subjective) was assessed for each sample after thawing. Percentage of individual motile sperm (motility) was noted.

\subsection{Sperm motility assessed by CASA}

Semen were diluted down to $10-20 \times 10^{6} \mathrm{sperm} / \mathrm{mL}$ and loaded into a Makler counting chamber (10 $\mu \mathrm{m}$ depth) at $37^{\circ} \mathrm{C}$. The CASA system consisted of a triocular optical phase contrast microscope (Nikon Eclipse 80i; Nikon; Tokyo, Japan), equipped with a warming stage at $37^{\circ} \mathrm{C}$ and a Basler A302fs digital camera (Basler Vision Technologies, Ahrensburg, Germany). The camera was connected to a computer by an IEEE 1394 interface. Images were captured and analyzed using the Sperm Class Analyzer (SCA2002) software (Microptic S.L.; Barcelona, Spain). Sampling was conducted using $\mathrm{a} \times 10$ negative phase contrast objective (no intermediate magnification). Image sequences were saved and analyzed afterwards. Software settings were adjusted to ram sperm. The standard parameter settings were as follows: 25 frames/s; $20-90 \mu \mathrm{m}^{2}$ for head area; VCL $>10 \mu \mathrm{m} / \mathrm{s}$ to classify a spermatozoon as motile. For each sperm, the software rendered the percentage of motile sperm (TM), the percentage of progressive motile sperm (PM) three velocity parameters (VCL: velocity according to the actual path $(\mu \mathrm{m} / \mathrm{s})$; VSL: velocity according to the straight path $(\mu \mathrm{m} / \mathrm{s})$; VAP: velocity according to the smoothed path $(\mu \mathrm{m} / \mathrm{s}), \mathrm{LIN}$ : linearity (\%); ALH: amplitude of the lateral displacement of the sperm head $(\mu \mathrm{m})$; and BCF: head beat-cross frequency, $(\mathrm{Hz})$. These parameters have been defined elsewhere (Mortimer, 1997).

\subsection{Flow cytometry analyses}

Sperm samples were analyzed using a Cytometer, Cytomics FC500 (Beckman Coulter, Brea, CA, USA). Excitation was provided by a $488 \mathrm{~nm}$ Argon-Ion laser. The FSC (forward - scattered light) and SSC (side-scattered light) signals were used to gate out debris (non-sperm events). FL1 photodetector (530/28BP filter) was used for YOPRO1, FITC-PNA, and JC-1; FL2 (575/26BP filter) for JC-1; FL3 (620SP filter) for PI events. The acquisition was controlled using the MXP software. All the parameters were read using logarithmic amplification. About 5000 sperm cells were acquired from each sample.

Staining solutions were prepared using SOF-HEPES ( $10 \mathrm{~mL}$ of SOF medium supplemented with $23.5 \mathrm{mg}$ of HEPES). Sperm were diluted in $0.5 \mathrm{~mL}$ of the different staining solutions in polypropylene tubes for flow cytometry (final concentration $5 \times 10^{6}$ sperm $/ \mathrm{mL}$ ).

\subsubsection{Sperm viability and apoptosis-like changes}

State of plasma membrane (apoptosis-like changes) with YOPRO1 and the viability with propidium iodide (PI) were assessed (García-Alvarez et al., 2009b). A staining solution using SOF-HEPES was prepared by adding $50 \mathrm{nM}$ YOPRO1, and $15 \mu \mathrm{M}$ PI. Amounts of $20 \mu \mathrm{L}$ of sample were diluted in $0.5 \mathrm{~mL}$ of staining solution in polypropylene tubes for flow cytometry. The tubes were allowed to equilibrate for $15 \mathrm{~min}$ in the dark and then analyzed by low cytometry. The PI stains the nucleus of sperm with damaged plasma membranes. YOPRO1 stains the nucleus when the membrane permeability increases, a phenomenon associated to apoptosis in other cell types (Martínez-Pastor et al., 2009). YOPRO1-/PI- were considered viable sperm (indicating live sperm with intact plasmalemma), whereas YOPRO1+/PI- were considered as sperm with continuous plasmalemma, but with apoptoticlike disorders.

\subsubsection{Assessment of mitochondrial membrane potential $\left(\Delta \Psi_{m}\right)$}

The lipophilic cationic probe JC-1 was used to assess the mitochondrial status of the sperm. According to the manufacturer (Molecular Probes, Invitrogen Life Sciences, Fullerton, CA, USA.) and as described Robles and MartínezPastor (2013), JC-1 changes reversibly its fluorescence from green (monomeric status) to orange (multimeric status) when the mitochondrial membrane potential is great. Sperm samples were diluted with SOF-HEPES to a concentration of $5 \times 10^{6} \mathrm{sperm} / \mathrm{mL}, 300 \mathrm{~mL}$ of each sample were transferred to a polypropylene tube, and $1.2 \mathrm{~mL}$ of JC-1 stock solution ( $0.7 \mathrm{mM} \mathrm{JC}-1$ in DMSO) was added. The tubes were incubated at $37^{\circ} \mathrm{C}$ for $30 \mathrm{~min}$ in the dark. The stained sperm samples were then analyzed by flow cytometry, which identified cells with great mitochondrial membrane potential (hMMP; orange-stained cells).

\subsubsection{Assessment of acrosomal integrity}

Acrosomal status was assessed in a $12 \mu \mathrm{M}$ PI and FITCPNA $1 \mu \mathrm{g} / \mathrm{mL}$ staining solution. The PNA (peanut agluttinin) binds specifically to the internal side of the external membrane of the acrosome, labeling acrosome-damaged sperm. The fluorescent technique allows distinguishing among four sperm populations: PI-/PNA- were considered as living cells with intact acrosomes, $\mathrm{PI}+$ /PNA - as dead cells with intact acrosomes, PI+/PNA+ as dead cells with damaged 

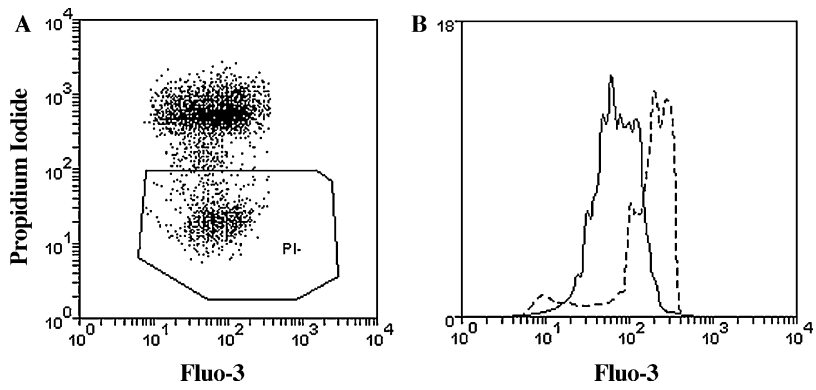

Fig. 1. Representative cytogram and histogram obtained by flow cytometry analysis of a ram sample after loading the sperm with Fluo-3, a specific stain for intracytoplasmatic calcium, and counterstained with propidium iodide (PI), a non-permeable membrane stain, for assessing viability. (A): Fluo-3/PI dot plot, showing a gate to discard PI positive sperm (membrane damaged). (B): Fluo-3/PI negative (Non-damaged membrane) histogram, showing only fluorescence from viable sperm (gated). The histogram shows fluorescence results from an untreated sample (solid line) and after incubating with $1 \mu \mathrm{M}$ of calcium ionophore (dashed line). The mean fluorescence was obtained from each histogram, and a rate was obtained by dividing the non-treated mean by the ionophore-incubated mean, resulting in an estimation of the intracellular calcium concentration. Data were obtained from Cytomics FC500 Cytometer (Beckman Coulter, Brea, CA, USA).

acrosomes and PI-/PNA+ as live cells with damaged acrosomes.

\subsubsection{Detection of intracelular calcium concentration}

To assess the amount of intracellular calcium existing in the cytoplasm and reserves held by the sperm, samples were stained in a $5 \mu \mathrm{M}$ fluo- 3 and $12 \mu \mathrm{M}$ PI in SWB (Sucrose Wash Buffer) as described by Harrison et al. (1993). The fluo-3 has affinity for $\mathrm{Ca}^{2+}$ and to a lesser extent by $\mathrm{Mg}^{2+}$; when it binds to these cations, it emits green fluorescence. Mean of green fluorescence of living cells (PI-) was evaluated (Fig. 1). A replicate was performed adding to a second tube $1 \mu \mathrm{M}$ of calcium ionophore (A23187) and incubating $10 \mathrm{~min}$. The average calcium content of viable sperm in each sample was estimated by the ratio of untreated and ionophore-treated tubes.

\subsection{Statistical analysis}

All statistical analysis was performed using SPSS for Windows version 17.0 (SPSS Inc., Chicago, IL, USA). All variables that were not normal were transformed using the arc sine (percentages) or decimal logarithm. Statistical signification was considered when $P<0.05$.
A preliminary study was conducted to estimate the effects of some environmental factors on fertility outcomes. These factors were: year and season of insemination, farm in which females were managed, technicians who perform the inseminations and the number of ewes inseminated per male. All factors showed a significant effect with the exception of number of ewes inseminated per male. Therefore, prior to examining the relationships among male fertility and sperm traits, fertility outcome was corrected by all these significant factors as a way to reduce the variability due to other factors than the sperm characteristics. The study of the relationships among male fertility by intrauterine insemination and sperm features were performed by using a uni-variate linear regression.

\section{Results}

\subsection{Semen evaluation}

The effects of sperm incubation either in the freezing extender or in the SOF medium are summarized in Tables 1 and 2. Table 1 shows several motility variables as yielded by the CASA system. No significant differences $(P>0.05)$ were detected between the two media after thawing and after $2 \mathrm{~h}$ of incubation. Motility parameters PM, VAP, VCL, VSL and ALH decreased during incubation, regardless of the medium used for incubation. Total motility, however, decreased $(P<0.05)$ only in those samples diluted with the freezing extender, while no significant differences were observed when a SOF medium $\left(38^{\circ} \mathrm{C}, 5 \%\right.$ $\mathrm{CO}_{2}$ ) was used.

Table 2 presents the effect of dilution and incubation during $2 \mathrm{~h}$ in the freezing extender $\left(37^{\circ} \mathrm{C}\right)$ and in the $\operatorname{SOF}\left(38^{\circ} \mathrm{C}, 5 \% \mathrm{CO}_{2}\right)$ on flow cytometry variables. Results showed an overall decrease in sperm quality as assessed by flow cytometry after incubation, whereas no significant differences were observed between the two media $(P>0.05)$.

\subsection{Correlations between sperm parameters and in vivo fertility}

The sperm samples used in this study were selected based on heterogeneity regarding its in vivo fertility. Three males were selected with an average fertility above $50 \%$ and three males with an average fertility below $50 \%$. Male fertility by intrauterine artificial insemination ranged from $22 \%$

Table 1

Sperm motility parameters assessed by the CASA system Sperm Class Analyzer (SCA $\left.{ }^{\circledR}\right)$. Values are expressed as Mean \pm S.E.M. Sperm analyses were conducted immediately after thawing or after dilution in Synthetic Oviductal Fluid (SOF), and after $2 \mathrm{~h}$ of incubation in the freezing medium ( $37^{\circ} \mathrm{C}$ ) or in $\operatorname{SOF}\left(38^{\circ} \mathrm{C}, 5 \% \mathrm{CO}_{2}\right)$.

\begin{tabular}{|c|c|c|c|c|c|c|c|c|c|}
\hline Time (h) & Treatment & TM & PM & VAP & VCL & VSL & LIN & ALH & $\mathrm{BCF}$ \\
\hline \multirow[t]{2}{*}{0} & Freezing extender & $83.8 \pm 3.8^{\mathrm{a}}$ & $24.8 \pm 4.2^{\mathrm{a}}$ & $70.1 \pm 3.9^{a}$ & $89.5 \pm 2.5^{\mathrm{a}}$ & $49.7 \pm 6.5^{\mathrm{a}}$ & $47.0 \pm 3.9^{a}$ & $2.9 \pm 0.2^{\mathrm{a}}$ & $4.9 \pm 0.2^{\mathrm{a}}$ \\
\hline & SOF & $79.8 \pm 4.0^{\mathrm{a}}$ & $21.6 \pm 3.9^{a}$ & $64.8 \pm 7.0^{\mathrm{a}}$ & $83.5 \pm 6.0^{\mathrm{a}}$ & $43.9 \pm 6.7^{\mathrm{a}}$ & $45.4 \pm 3.2^{\mathrm{a}}$ & $2.8 \pm 0.2^{\mathrm{a}}$ & $4.69 \pm 0.3^{\mathrm{a}}$ \\
\hline \multirow[t]{2}{*}{2} & Freezing extender & $43.8 \pm 11.9^{b}$ & $9.2 \pm 2.6^{\mathrm{b}}$ & $37.0 \pm 7.4^{* b}$ & $49.9 \pm 7.3^{* \mathrm{~b}}$ & $25.6 \pm 5.7^{* b}$ & $44.2 \pm 3.6^{a}$ & $2.1 \pm 0.1^{\mathrm{b}}$ & $4.1 \pm 0.6^{* * * \mathrm{~b}}$ \\
\hline & SOF & $63.1 \pm 10.0^{\mathrm{a}}$ & $8.8 \pm 1.2^{\mathrm{b}}$ & $29.4 \pm 2.3^{b}$ & $43.1 \pm 1.9^{\mathrm{b}}$ & $19.3 \pm 2.12^{b}$ & $38.4 \pm 1.6^{a}$ & $2.1 \pm 0.1^{\mathrm{b}}$ & $3.3 \pm 0.2^{b}$ \\
\hline
\end{tabular}

Motility parameters: TM: \% total motile sperm, PM: \% sperm with a progressive movement; VAP: velocity according to the smoothed path ( $\mu$ m/s), VCL: velocity according to the actual path ( $\mu \mathrm{m} / \mathrm{s})$; VSL: velocity according to the straight path; LIN: linearity (\%); ALH: amplitude of the lateral displacement of the sperm head; $\mu \mathrm{m}$ ); the BCF (head beat-cross frequency, Hz). ${ }^{\text {ab }}$ Different letters indicate differences between incubation times $(P<0.05) .{ }^{*}$ correlation with fertility in vivo $(P<0.05)$. ${ }^{* * *}$ correlation with fertility in vivo $(P<0.001)$. 
Table 2

Results of sperm parameters evaluated by flow cytometry and its relation to in vivo fertility assessed by artificial insemination. Values are expressed as (Mean \pm S.E.M.) provided by cytometry and their relation to fertility. Sperm analyses were conducted immediately after thawing or dilution in SOF and after $2 \mathrm{~h}$ of incubation, either in the freezing medium $\left(37^{\circ} \mathrm{C}\right)$ or after dilution in Synthetic Oviductal Fluid (SOF) medium $\left(38^{\circ} \mathrm{C}, 5 \% \mathrm{CO}_{2}\right)$.

\begin{tabular}{|c|c|c|c|c|c|c|}
\hline $\begin{array}{l}\text { Time } \\
\text { (h) }\end{array}$ & Treatment & $\begin{array}{l}\text { Viability } \\
(\%)\end{array}$ & $\begin{array}{l}\text { hMMP } \\
(\%)\end{array}$ & $\begin{array}{l}\text { Apoptotic-like membrane } \\
\text { changes }(\%)\end{array}$ & $\begin{array}{l}\text { Acrosomal } \\
\text { integrity (\%) }\end{array}$ & $\begin{array}{l}\text { Intracellular calcium rate (\%) } \\
\text { (viable cells) }\end{array}$ \\
\hline \multirow[t]{2}{*}{0} & Freezing extender & $26.5 \pm 4.7^{\mathrm{a}}$ & $29.5 \pm 4.3^{\mathrm{a}}$ & $3.9 \pm 0.4^{\mathrm{a}}$ & $19.4 \pm 3.0^{\mathrm{a}}$ & $46.0 \pm 9.0^{\mathrm{a}}$ \\
\hline & SOF & $32.7 \pm 3.3^{\mathrm{a}}$ & $29.8 \pm 5.1^{\mathrm{a}}$ & $5.7 \pm 0.8^{\mathrm{a}}$ & $22.7 \pm 2.8^{\mathrm{a}}$ & $39.7 \pm 9.0^{\mathrm{a}}$ \\
\hline \multirow[t]{2}{*}{2} & Freezing extender & $15.3 \pm 2.4^{\mathrm{a}}$ & $14.6 \pm 2.7^{\mathrm{b}}$ & $5.0 \pm 1.1^{\mathrm{a}}$ & $9.8 \pm 1.8^{\mathrm{a}}$ & $55.9 \pm 9.0^{\mathrm{b}}$ \\
\hline & SOF & $24.1 \pm 3.4^{\mathrm{a}}$ & $16.3 \pm 3.8^{a}$ & $6.7 \pm 1.6^{\mathrm{a}}$ & $12.4 \pm 3.2^{\mathrm{a}}$ & $54.4 \pm 9.0^{\mathrm{a}}$ \\
\hline
\end{tabular}

Cytometry parameters: Positive sign (+) indicates cell staining, negative sign (-) indicate the lack of staining for each flourochrome. PI: propidium iodide. Viability: \% of YO-PRO-/PI- (membrane intact) sperm; hMMP: \% of sperm with high mitochondrial membrane potential (JC-1 +); Apoptotic-like membrane changes: \% of YO-PRO+/PI- sperm; acrosomal integrity: \% of PNA+/PI- sperm; Intracellular calcium rate (viable cells): result of dividing the average fluo-3 mean fluorescence by the average fluo-3 mean fluorescence after incubating with $1 \mu \mathrm{M}$ calcium ionophore, as percentage. ${ }^{\mathrm{a}, \mathrm{b}}$ Different letters indicate differences between incubation times $(P<0.05)$.

to $83 \%$, with a mean value of $44 \%$. There were differences in fertility among males $(P=0.003)$.

The possible relation between kinematic and flow cytometry variables with in vivo fertility was studied using a lineal regression analysis. There were relationships between some kinematic parameters and field fertility only after $2 \mathrm{~h}$ of incubation in the freezing extender. In this regard, average-path velocity (VAP), the curvilinear velocity (VCL) and the head beat-cross frequency $(\mathrm{BCF})$, showed a high positive correlation with fertility $(P=0.044$ $\left(R^{2}=0.678\right), P=0.027\left(R^{2}=0.745\right)$ and $P=0.006\left(R^{2}=0.852\right)$, respectively; Fig. 2; Table 1).

\section{Discussion}

Recently, García-Alvarez et al. (2009a) showed that heterologous in vitro fertilization was a good procedure to predict the fertility of ram semen, unlike sperm evaluation by flow cytometry. However, methods based in IVF are costly in time needed to conduct the procedure and from a financial perspective. Therefore, in the present study two objectives were proposed. First, the objective was to study the quality of cryopreserved sperm using an incubation model in freezing extender or IVF media to determine if these stressful conditions could improve the relation between sperm quality variables (as assessed after incubation) with field fertility. Therefore, it could be concluded from these results whether these incubation models were practical, as a standard method for improving sperm quality assessment. Complementary with the first objective, the second objective aimed to identify laboratory techniques that would be most appropriate for, in the experimental approach defined by the first objective, to quickly and effectively evaluate the fertility potential of a sperm sample.

Motility has been considered one of the most important characteristics associated with the fertilizing ability of sperm (Saacke and White, 1972). In the present study, a decrease in motility variables was detected after the incubation, reflecting the stressful situation that sperm incur in these conditions. Interestingly, a positive relationship was detected among several kinematic variables (VCL, VAP, VSL, BCF) measured after the incubation in the extender and field fertility. To our knowledge, this is the first time a relationship was demonstrated between motility assessed by CASA and fertility of cryopreserved ram sperm. The difference in the present study with previous studies is the inclusion of a post-thawing incubation prior to the assessment. Thus, O'Meara et al. (2008) and García-Alvarez et al. (2010) did not detect a significant relationship between fertility and sperm quality (functional parameters or CASA, respectively) in thawed ram sperm. Results of the present study show the importance of pre-treating sperm before assessing the quality (in this case, submitting them to incubation at $37^{\circ} \mathrm{C}$ ). Malo et al. (2005) found differences in fertility between red deer stags related strongly to sperm swimming velocity parameters (VCL, VSL and VAP), and results of the present study support the hypothesis that sperm velocity is one of the key features in the process of fertilization, which has been also demonstrated in a large number of taxa (Gage et al., 2004; Holt et al., 1989). Greater motility is a result of a physiologically functional sperm, and sperm with decreasing motility are indicative of decreased sperm metabolism or failing organelles. This might indicate not only a decreased ability to reach the oocyte (of lesser importance in laparoscopic insemination), but reflects a lesser ability to undergo capacitation, the production of an excess of free radicals or to execute key steps in egg fertilization (Aitken et al., 2012; MartínezPastor et al., 2009). Results of the present study agree with studies in other species (bull: Amann et al., 2000; Farrell et al., 1998; Kathiravan et al., 2008; goat: Fernandez-Santos et al., 2011), which show that kinematic parameters as VCL, VSL and VAP are related to fertility. Other researchers have found positive correlations between different velocity parameters and fertility in human sperm (Fetterolf and Rogers, 1990).

Flow cytometry has been successful as a tool for the study of several physiological features of sperm (Petrunkina et al., 2007), and many tests have been related with in vivo fertility (Gillan et al., 2003; Januskauskas et al., 2000; Wilhelm et al., 1996). However, the study of ram sperm by flow cytometry has not been related to field fertility. For instance, O'Meara et al. (2008) did not found that viability or acrosomal status of ram sperm studied by flow cytometry were related to in vivo fertility. In 2007, Rodríguez-Martínez and Barth indicated that both modern sperm evaluation techniques and conventional techniques have been related to fertility, but these relationships are modest and quite variable between laboratories.

It must be pointed out that these studies did not make use of a pre-treatment of thawed sperm prior to the study 

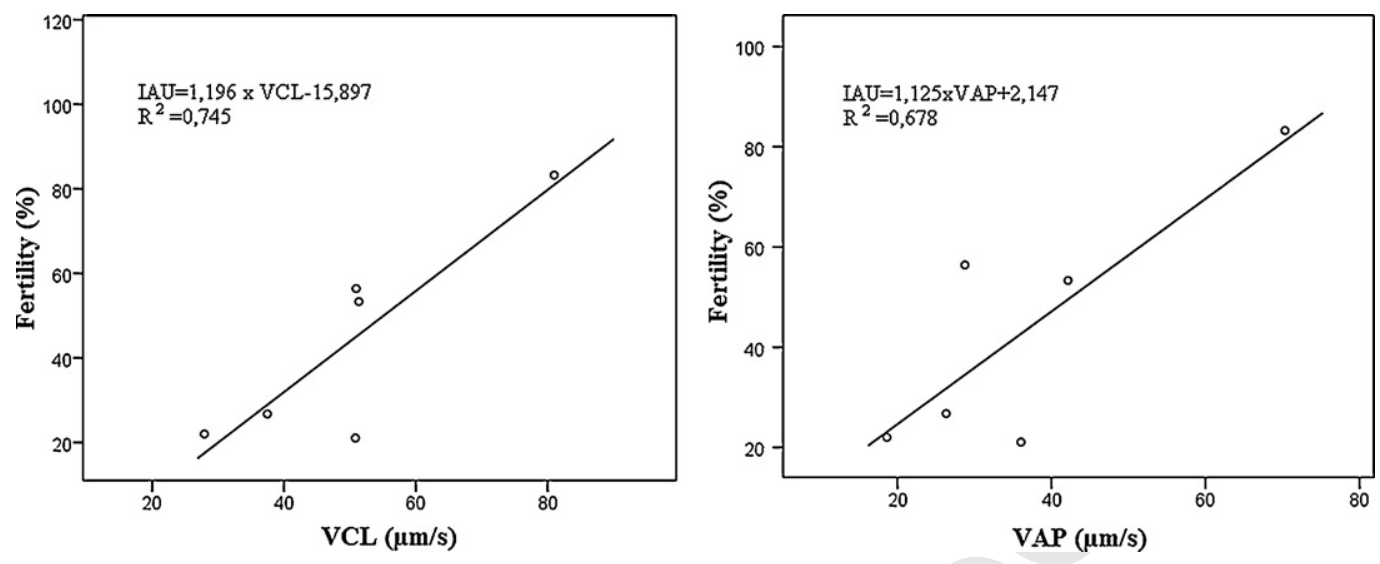

Fig. 2. Relationship between in vivo male fertility and VCL (velocity according to the actual path) and VAP (velocity according to the smoothed path). Regression lines and their equations are showed $(P<0.05)$. Data were obtained using a computer-assisted sperm analysis (CASA) system (Sperm Class Analyzer, SCA2002, Microptic S.L.: Barcelona, Spain).

of sperm quality. The incubation of sperm at physiological of above physiological temperatures is a challenge that may help to uncover the authentic fertility potential of the sample. This kind of treatment can be helpful for other kind of experiments. For instance, in a recent study the post-thawing quality of red deer sperm cryopreserved with different antioxidants were not very differentfrom the control, but after incubating the samples at $39^{\circ} \mathrm{C}$ many differences were detected (Anel-López et al., 2012). Because in the present study it was found that there was a direct relationship between motion parameters and fertility, and mitochondria have been considered a fundamental organelle to sperm physiology (Mukai and Okuno, 2004; Peña et al., 2009), it would be logical to find a relationship between mitochondrial status and fertility. There, however, was not any relation between mitochondrial activity as measured using JC-1, and fertility in the present study. In this regard, Volpe et al. (2009) and Cheuquemán et al. (2011) indicated that JC-1 is suitable for detection of inner mitochondrial membrane potential changes in canine sperm, but it should always be associated with an objective motility analysis to avoid an incorrect evaluation of potential sperm fertility. García-Alvarez et al. (2009a) also showed that mitochondrial membrane potential of ram sperm, analyzed with MitoTracker deep red, was unrelated to fertility. Indeed, it has been considered that the main role of the sperm mitochondria was the production of energy for sperm motility, but this concept is under assessment and the roles of mitochondria will likely be broadened as more research assessing these roles is conducted (Marin et al., 2003; Miki et al., 2004; Mukai and Okuno, 2004). Mitochondria also have a crucial role in diverse cellular functions apart from energy production, such as modulation of the redox balance, osmotic regulation and $\mathrm{Ca}^{++}$homeostasis (Peña et al., 2009). Therefore, the assessment of mitochondrial status could eventually offer important information relative to the sperm fertilizing ability, but this might require other experimental approaches.

Different researchers have demonstrated that intracytoplasmatic calcium efflux is a necessary component for capacitacion (Gualtieri et al., 2005). Although in the present study greater calcium concentrations were detected after incubation, there was not any relation between fertility and the relative intra-cellular calcium concentration with any treatment. Thus, the concentration of $\mathrm{Ca}^{2+}$ in the sperm after thawing or after incubation did not reflect the fertility of the sperm samples. That does not mean that $\mathrm{Ca}^{2+}$ concentrations are irrelevant. Measurement of the $\mathrm{Ca}^{2+}$ profile after treating sperm with progesterone or other physiological signals could offer relevant information related to sperm fertility (Arienti et al., 2010). The primary conclusion from the present research is that thawed semen samples with a greater sperm velocity is related to a greater field fertility, but only when measurements were conducted after $2 \mathrm{~h}$ of incubation in the freezing extender. Interestingly, incubation in SOF in conditions seeking to mimic the female oviductal environment did not yield any significant relationship with fertility. To our knowledge, no other researchers have found this relationship between sperm motility parameters and in vivo fertility of rams following intrauterine artificial insemination of ewes with frozen-thawed semen. Results cannot be generalized with conclusions of the present study, because of the limited number of males involved. Nevertheless, the experimental approach in the present study evaluating the semen samples after a $2 \mathrm{~h}$ incubation at $37^{\circ} \mathrm{C}$ in the freezing medium merits further research, and it could be the basis of protocols for predicting the in vivo fertility of frozen-thawed ram sperm samples.

\section{Acknowledgements}

This research was supported by Education and Science Council (JCCM, Spain) grant (PAI09-0006-3806). Enrique del Olmo is supported by a grant for training of technical personnel associated with the project PTA2008-0858-P (Spanish Ministry of Science and Innovation, MICINN). Manuel Ramón is supported by the DOC-INIA program, and Felipe Martínez-Pastor is supported by the Ramón y Cajal program (RYC-2008-02560, Spanish Ministry of Science and Innovation, MICINN) 


\section{References}

Aitken, R.J., Nixon, B., Lin, M., Koppers, A.J., Lee, Y.H., Baker, M.A., 2007. Proteomic changes in mammalian spermatozoa during epididymal maturation. Asian J. Androl. 9, 554-564.

Aitken, R.J., Gibb, Z., Mitchell, L.A., Lambourne, S.R., Connaughton, H.S., De Iuliis, G.N., 2012. Sperm motility is lost in vitro as a consequence of mitochondrial free radical production and the generation of electrophilic aldehydes but can be significantly rescued by the presence of nucleophilic thiols. Biol. Reprod. 87, $1-11$.

Amann, R.P., Seidel Jr., G.E., Mortimer, R.G., 2000. Fertilizing potential in vitro of semen from young beef bulls containing a high or low percentage of sperm with a proximal droplet. Theriogenology 54, 1499-1515.

Anel-López, L., Alvarez-Rodríguez, M., García-Alvarez, O., Alvarez, M., Maroto-Morales, A., Anel, L., de Paz, P., Garde, J.J., Martínez-Pastor, F., 2012. Reduced glutathione and Trolox (vitamin E) as extender supplements in cryopreservation of red deer epididymal spermatozoa. Anim. Reprod. Sci., http://dx.doi.org/10.1016/j.anireprosci.2012.09.001.

Arienti, G., Mazzoni, M., Spapperi, C., Saccardi, C., Palmerini, C.A., 2010. Effect of FSH and progesterone on human spermatozoa cytosolic calcium. J. Steroid Biochem. Mol. Biol. 120, $180-183$.

Cheuquemán, C., Bravo, P., Treulén, F., Giojalas, L., Villegas, J., Sánchez, R., Risopatrón, J., 2011. Sperm membrane functionality in the dog assessed by flow cytometry. Reprod. Domest. Anim., http://dx.doi.org/10.1111/j.1439-0531.2011.01798.x.

Farrell, P.B., Presicce, G.A., Brockett, C.C., Foote, R.H., 1998. Quantification of bull sperm characteristics measured by computer-assisted sperm analysis (CASA) and the relationship to fertility. Theriogenology 48 , 871-879.

Fernandez-Santos, M.R., Soler, A.J., Ramón, M., Ros-Santaella, J.L., MarotoMorales, A., García-Alvarez, O., Bisbal, A., Garde, J.J., Santiago-Moreno, J., 2011. Effect of post-mortem time on post-thaw characteristics of Spanish ibex (Capra pyrenaica) spermatozoa. Anim. Reprod. Sci. 129, $56-66$.

Fetterolf, P.M., Rogers, B.J., 1990. Prediction of human sperm penetrating ability using computerized motion parameters. Mol. Reprod. Dev. 27, 326-331.

Fiser, P.S., Ainsworth, L., Fairfull, R.W., 1987. Evaluation of a new extender and different processing procedures for cryopreservation of ram semen. Theriogenology 28, 599-607.

Gage, M.J., Macfarlane, C.P., Yeates, S., Ward, R.G., Searle, J.B., Parker, G.A. 2004. Spermatozoal traits and sperm competition in Atlantic salmon relative sperm velocity is the primary determinant of fertilization success. Curr. Biol. 14, 44-47.

García-Alvarez, O., Maroto-Morales, A., Martínez-Pastor, F., FernandezSantos, M.R., Esteso, M.C., Pérez-Guzmán, M.D., Soler, A.J., 2009a. Heterologous in vitro fertilization is a good procedure to assess the fertility of thawed ram spermatozoa. Theriogenology 71 , 643-650.

García-Alvarez, O., Maroto-Morales, A., Martínez-Pastor, F., Garde, J.J., Ramón, M., Fernandez-Santos, M.R., Esteso, M.C., Pérez-Guzmán, M.D., Soler, A.J., 2009b. Sperm characteristics and in vitro fertilization ability of thawed spermatozoa from Black Manchega ram: electroejaculation and postmortem collection. Theriogenology 72 , $160-168$.

García-Alvarez, O., Maroto-Morales, A., Ramón, M., del Olmo, E., Montoro, V., Dominguez-Rebolledo, A.E., Bisbal, A., Jiménez-Rabadán, P., Pérez-Guzmán, M.D., Soler, A.J., 2010. Analysis of selected sperm by density gradient centrifugation might aid in the estimation of in vivo fertility of thawed ram spermatozoa. Theriogenology 74 , 979-988.

Gillan, L., Evans, G., Maxwell, W.M.C., 2003. Flow cytometric evaluation of sperm parameters in relation to fertility potential. Theriogenology $63,445-457$.

Gravance, C.G., Davis, R.O., 1995. Automated sperm morphometry analysis (ASMA) in the rabbit. J. Androl. 16, 88-93.

Gualtieri, R., Boni, R., Tosti, E., Zagami, M., Talevi, R., 2005. Intracellular calcium and protein tyrosine phosphorylation during the release of bovine sperm adhering to the fallopian tube epithelium in vitro. Reproduction 129, 51-60.

Hallap, T., Nagy, S., Jaakma, U., Johannisson, A., RodríguezMartínez, H., 2006. Usefulness of a triple fluorochrome combination Merocyanine 540/YOPRO1/Hoechst 33342 in assessing membrane stability of viable frozen-thawed spermatozoa from Estonian Holstein AI bulls. Theriogenology 65, $1122-1136$.
Harrison, R.A., Mairet, B., Miller, N.G., 1993. Flow cytometric studies of bicarbonate-mediated $\mathrm{Ca}^{2+}$ influx in boar sperm populations. Mol. Reprod. Dev. 35, 97-208.

Holt, W.V., Shenfield, F., Leonard, T., Hartman, T.D., North, R.D., Moore, H.D., 1989. The value of sperm swimming speed measurements in assessing the fertility of human frozen semen. Hum. Reprod. 4, 292-297.

Januskauskas, A., Johannisson, A., Söderquist, L., Rodríguez-Martínez, H., 2000. Assessment of sperm characteristics post-thaw and response to calcium ionophore in relation to fertility in Swedish dairy AI bulls. Theriogenology 53, 859-875.

Kathiravan, P., Kalatharan, J., Edwin, M.J., Veerapandian, C., 2008. Computer automated motion analysis of crossbred bull spermatozoa and its relationship with in vitro fertility in zona-free hamster oocytes. Anim. Reprod. Sci. 104, 9-17.

Malo, A.F., Garde, J.J., Soler, A.J., García, A.J., Gomendio, M., Roldan, E.R., 2005. Male fertility in natural populations of red deer is determined by sperm velocity and the proportion of normal spermatozoa. Biol. Reprod. 72, 822-829.

Marin, S., Chiang, K., Bassilian, S., Lee, W.N., Boros, L.G., Fernandez-Novell, J.M., Centelles, J.J., Medrano, A., Rodriguez-Gil, J.E., Cascante, M., 2003. Metabolic strategy of boar spermatozoa revealed by a metabolomic characterization. FEBS Lett. 554, 342-346.

Marquez, B., Suarez, S.S., 2007. Bovine sperm hyperactivation is promoted by alkaline-stimulated $\mathrm{Ca}^{2+}$ influx. Biol. Reprod. 76, 660-665.

Martínez-Pastor, F., Aisen, E., Fernandez-Santos, M.R., Esteso, M.C., Maroto-Morales, A., García-Alvarez, O., Garde, J.J., 2009. Reactive oxygen species generators affect quality parameters and apoptosis markers differently in red deer spermatozoa. Reproduction 137, 225-235.

Martínez-Pastor, F., Mata-Campuzano, M., Alvarez-Rodríguez, M., Alvarez, M., Anel, L., de Paz, P., 2010. Probes and techniques for sperm evaluation by flow cytometry. Reprod. Domest. Anim. 45, 67-78.

Maxwell, W.M.C., Watson, P.F., 1996. Recent progress in the preservation of ram semen. Anim. Reprod. Sci. 42, 55-65.

Miki, K., Qu, W., Goulding, E.H., Willis, W.D., Bunch, D.O., Strader, L.F., Perreault, S.D., Eddy, E.M., O'Brien, D.A., 2004. Glyceraldehyde 3phosphate dehydrogenase-S, a sperm-specific glycolytic enzyme, is required for sperm motility and male fertility. Proc. Natl. Acad. Sci. U. S. A. 101, 16501-16506.

Mortimer, S.T., 1997. A critical review of the physiological importance and analysis of sperm movement in mammals. Hum. Reprod. Update 3, 403-439.

Mukai, C., Okuno, M., 2004. Glycolisis plays a major role for adenosine triphosphate supplementation in mouse sperm flagellar movement. Biol. Reprod. 71, 540-547.

O'Meara, C.M., Hanrahan, J.P., Prathalingam, N.S., Owen, J.S., Donovan, A., Fair, S., Ward, F., Wade, M., Evans, A.C., Lonergan, P., 2008. Relationship between in vitro sperm functional tests and in vivo fertility of rams following cervical artificial insemination of ewes with frozen-thawed semen. Theriogenology 69, 513-522.

Papadopoulos, S., Hanrahan, J.P., Donovan, A., Duffy, P., Boland, M.P., Lonergan, P., 2005. In vitro fertilization as a predictor of fertility from cervical insemination of sheep. Theriogenology 63, 150-159.

Peña, F.J., Rodríguez-Martínez, H., Tapia, J.A., Ortega Ferrusola, C., González Fernandez, L., Macías García, B., 2009. Mitochondria in mammalian sperm physiology and pathology: a review. Reprod. Domest. Anim. 44, 345-349.

Petrunkina, A.M., Waberski, D., Günzel-Apel, A.R., Töpfer-Petersen, E., 2007. Determinants of sperm quality and fertility in domestic species. Reproduction 134, 3-17.

Robles, V., Martínez-Pastor, F., 2013. Flow cytometric methods for sperm assessment. Methods Mol. Biol. 927, 175-186.

Rodríguez-Martínez, H., 2003. Laboratory semen assessment and prediction of fertility: still utopia. Reprod. Domest. Anim. 38, 312-318.

Rodríguez-Martínez, H., Barth, A.D., 2007. In vitro evaluation of sperm quality related to in vivo function and fertility. Soc. Reprod. Fertil. Suppl. 64, 39-54.

Saacke, R.G., White, J.M., 1972. Semen quality test and their relationship to fertility. In: In Proceedings of the $4^{\text {th }}$ Technical Conference on Artificial Insemination and Reproduction, NAAB, Columba, MO, pp. 22-27.

Schneider, C.S., Ellington, J.E., Wright Jr., R.W., 1999. Relationship between bull field fertility and in vitro embryo production using sperm

583

584

585
586

586

588

589

590
591

591

593

5

596

59

59

600

60

602
603

60

605

607

608

60

61

61

61

615

61

61

61

62

62

62

62

62

62

629

63

631
632

632
633
634

634

636

637

638

639
640

641

642

64

644

645
646

647

648
649

650

651 
preparation methods with and without somatic cell co-culture. Theriogenology 51, 1085-1098.

Soler, A.J., Poulin, N., Fernandez-Santos, M.R., Cognie, Y., Esteso, M.C., Garde, J.J., Mermillod, P., 2008. Heterologous in vitro fertility evaluation of cryopreserved Iberian red deer epididymal spermatozoa with zona-intact sheep oocytes and its relationship with the characteristics of thawed spermatozoa. Reprod. Domest. Anim. 43, 293-298.

Volpe, S., Leoci, R., Aiudi, G., Lacalandra, G.M., 2009. Relationship between motility and mitochondrial functional status in canine spermatozoa. Reprod. Domest. Anim. 44, 275-278.
Wilhelm, K.M., Graham, J.K., Squires, E.L., 1996. Comparison of the fertility of cryopreserved stallion spermatozoa with sperm motion analyses, flow cytometric evaluation, and zona-free hamster oocyte penetration. Theriogenology 46, 559-578.

Zhang, B.R., Larsson, B., Lundeheim, N., Rodríguez-Martínez, H., 1998. Sperm characteristics and zona pellucida binding in relation to field fertility of frozen-thawed semen from dairy AI bulls. Int. J. Androl. 21, 207-216. 